\title{
Xarxa Llull: The University Network of Catalan Studies Abroad
}

\author{
Josep-Anton Fernàndez * (Àrea de Llengua i Universitats, Institut Ramon Llull, Barcelona) \\ jfernandez@1lull.catｈttp://orcid.org/0000-0003-1672-2414
}

\begin{abstract}
This article provides an outline of the network of universities where Catalan is taught outside the Catalan-speaking territories. This network is coordinated and managed by the Institut Ramon Llull, the public body created by the governments of Catalonia and the Balearic Islands and the city of Barcelona with the mission to promote the Catalan language and culture abroad. It consists of 145 universities in 28 countries, of which 87 universities receive funding from the IRL. The article describes the main characteristics and activities of this network, defines the value it creates for the various stakeholders that participate in it, and outlines its main objectives and projects for the immediate future.
\end{abstract}

Keywords: Catalan studies; higher education; modern languages; Institut Ramon Llull; international cultural promotion.

\section{A global network for a medium-sized language}

Xarxa Llull, the university network of Catalan studies abroad, consists of 145 universities in 28 countries where the Catalan language and culture are taught. Out of this total number, 87 universities currently receive funding from the Institut Ramon Llull (IRL) in order to partially cover the costs of teaching. This network was founded by the Government of Catalonia in 1988, when the Comissió de promoció de l'ensenyament del català a les universitats de fora de l'àmbit territorial de Catalunya was set up. The Institut Ramon Llull took over the coordination of this university network in 2002, after it was founded by the governments of Catalonia and the Balearic Islands (later joined by the city of Barcelona).

Xarxa Llull forms part of the Government of Catalonia's policies towards the international promotion of Catalan language and culture, which are implemented by the Institut Ramon Llull. Within this general framework, the main objective of the policies carried out by the IRL in the higher education sector is to guarantee the presence of Catalan studies at universities abroad, either through the maintenance or the consolidation of existing programmes, or through the creation of new programmes in new universities following criteria of academic excellence. These policies also aim at making Catalan studies more competitive through the constant improvement of the quality of the teaching body and by setting up a variety of programmes for students. By their own nature these policies require continuity, supervision, and long-term planning.

\footnotetext{
* Josep-Anton Fernàndez is Head of the Language and Universities Department of the Institut Ramon Llull (Barcelona), a public organisation that promotes Catalan language and culture abroad. He holds a BA in Catalan Language from the Universitat Autònoma de Barcelona and a PhD in Modern Languages from the University of Cambridge. He is currently on secondment from the Universitat Oberta de Catalunya where he teaches Catalan literature and culture. He was previously Senior Lecturer in Catalan at Queen Mary, University of London. He has published extensively on Catalan literature and culture, cinema and television and on issues of gender and sexuality.
} 
In the last ten years, the level of curricular development of Catalan studies at universities abroad has been growing thanks to the work of the IRL, the interest of the students, and the commitment of the universities. Currently, 20 universities offer officially recognised specialisations in Catalan studies, in the form of minors, Nebenfach, licences, or Bachelor's degrees. In the academic year 2015-2016, approximately 650 modules on Catalan language and culture were offered, into which some 6,800 students were registered. Besides, five institutions of great international prestige - the Sorbonne in Paris, Queen Mary University of London, University of Chicago, Stanford University, and the Graduate Center of the City University of New York-host chairs or research centres in Catalan studies, which organise high-profile conferences and lectures, or invite visiting professors to teach at postgraduate level.

It is not by chance that prestigious names such as the Sorbonne or Chicago are mentioned here. Indeed, guaranteeing the presence of Catalan studies at universities abroad necessitates a policy of active promotion in which the IRL plays a crucial role in choosing the higher education institutions where Catalan studies should be present. This kind of policy is fully adequate to the dimensions of the Catalan language: since Catalan is not a global language like English, French, or Spanish, the policies of the IRL do not aim at achieving a very large number of universities, but instead to be present in the best universities of each country and in academic and research environments of international excellence. Thus, Xarxa Llull boasts highly prestigious institutions such as the universities of Oxford, Cambridge, Birmingham, or Bristol in the United Kingdom; the École Normale Supérieure de Lyon or the Université de Toulouse-Jean Jaurès in France; the universities of Venice-Ca' Foscari, Turin, or Bologna in Italy; Freiburg, Heidelberg, or Humboldt Universität of Berlin in Germany; Harvard University, UCLA, or UC Berkeley in the United States of America; the Universidad Nacional Autónoma de México and the Universidade de São Paulo in Brazil; and many others. In fact, out of 87 universities funded by the Institut Ramon Llull, 55 (that is, 63\%) are amongst the 500 top higher education institutions in the 2016 Academic Ranking of World Universities (the "Shanghai Ranking"), and 16 (that is, 18\%) are in the top 100 world universities.

In order to ensure the competitiveness of Catalan studies, the IRL promotes a programme of academic and cultural activities at universities abroad. This programme aims to enhance the visibility and the prestige of Catalan culture in these universities, and to develop in each department a social, cultural, and academic environment around Catalan studies that makes it attractive to students and ensures the presence of the discipline in the academic and institutional life of the universities. The IRL also promotes programmes for students intended to enhance their linguistic competence and their knowledge of Catalan culture and society, and to help them develop skills and knowledge that will be valuable in their professional life. These programmes include, for example, summer language courses in various locations in the Catalan-speaking territories, literary translation seminars, and internships in Catalan businesses, institutions, and non-governmental organisations. Finally, as the official body for the certification of Catalan language knowledge abroad, the IRL offers students the possibility of taking the official language exams.

An essential process in the running of Xarxa Llull is the selection and training of the teaching body. The selection of teachers is carried out by means of a public call that is highly competitive: in 2015 there were 218 candidates for 25 posts, and in 2016, 127 candidates for 14 posts. Teachers are selected on the basis of the requirements set out by the universities, representatives of which are able to interview short-listed candidates in order to make the final decisions. Although geographical origin is not taken into account in the selection process, overall the teaching body of Xarxa Llull shows a good representation of all the Catalan-speaking territories (Table 1). 
Table 1. Geographical origin of Xarxa Llull's teaching body in the academic year 2016-2017 (data refers to universities funded by the IRL).

\begin{tabular}{lc}
\hline Territory & Number of teachers \\
\hline Catalonia & 57 \\
Valencia & 10 \\
Balearic Islands & 9 \\
Other & 6 \\
Total & $\mathbf{8 5}$
\end{tabular}

Xarxa Llull's teachers have excellent academic qualifications, are highly trained in teaching and learning methodologies, and are innovative and very dynamic when it comes to the development of a social and academic environment around Catalan studies. The training programme organised by the Institut Ramon Llull plays a vital role in maintaining these levels of quality and commitment. The main training activities are weekend-long courses periodically held in the countries or geographical areas with the largest concentration of universities, and particularly the Jornades Internacionals per a Professors de Català, which will reach their 31st edition in 2017, and which bring together around a hundred teachers each summer at a university of the Catalan-speaking territories to attend lectures, presentations, and workshops.

\section{A highly valuable network}

The importance of Xarxa Llull, the university network of Catalan studies abroad, goes well beyond the purely academic sphere. Indeed, together with the Catalan communities abroad, Xarxa Llull constitutes the only stable and constant presence of Catalan culture in the world. Besides disseminating knowledge about Catalan culture and promoting a positive image of Catalonia, Xarxa Llull is an important element in the international projection of Catalan culture-to which it contributes a constant and numerous audience-and plays a role in economic and cultural exchanges. Furthermore, Xarxa Llull is a source of opportunities in different areas: it creates professional opportunities for Catalan graduates, facilitates institutional contacts between Catalan and international universities, and offers opportunities for international collaborations for Catalan academics in the fields of the humanities and the social sciences and their departments.

In 2016 the Government of Catalonia invested through the Institut Ramon Llull 1.5 million euros in maintaining this structure (within the IRL's total budget of 7.5 million euros). Compared with the budget of 115 million euros that the Spanish government allocated to the Instituto Cervantes in 2016, the economic cost of Xarxa Llull certainly becomes a minuscule figure. Even so, the return yielded by Xarxa Llull amply exceeds the investment costs, because the presence of Catalan studies through this university network creates value for a wide variety of stakeholders:

- It offers students the discovery of a rich and complex culture, as well as an asset that differentiates them from graduates of major languages; it also provides students with opportunities in terms of mobility, professional development, research, and participation in networks of various kinds.

- It provides Catalan studies teachers with employment opportunities in world-class universities, facilitates their professional growth by means of an enriching experience in a different culture and university system, and gives them access to international research groups. 
- It provides universities abroad with a richer, more competitive curricular offer that differentiates them from their competitors, and it enhances their research in the fields of the humanities and the social sciences.

- It contributes to the Catalan university system an important piece of its internationalisation, as it helps Catalan universities establish valuable relationships with their counterparts abroad, it facilitates the integration of international students, it enhances the mobility of academic staff, and constitutes a significant means for the international dissemination of Catalan research production in the humanities and the social sciences.

- It affords Catalan society as a whole a significant value in terms of the strategic, political, cultural, economic, and diplomatic interests of the country: Xarxa Llull promotes a positive international image of Catalonia and spreads knowledge about it around the world; it is a crucial element of the international promotion of Catalan culture in highly prestigious spheres, and contributes a sizeable, constant audience; it guarantees the presence of Catalan language and culture at universities abroad; through its research centres and chairs for visiting professors, it enhances the prestige and the visibility of Catalan studies, and Catalan language and culture generally; it trains professionals (for instance, translators, teachers, specialists in cultural management) whose specialised knowledge is an asset regarding the international projection of Catalan culture; it contributes to cultural and economic exchanges with strategic countries; and it is an important instrument in cultural diplomacy.

\section{Objectives for the future and upcoming projects}

The higher education sector is experiencing a profound transformation in many of the countries where Xarxa Llull is present. For example, in several countries university governance has evolved towards models that emphasise the economic efficiency of academic programmes and structures, resulting in mergers of departments into larger units, and of universities into much bigger institutions. Within these new governance models, policies towards modern languages have questioned the cost-efficiency of these disciplines, especially when it comes to less-commonly taught languages. In Europe, the introduction of the European Higher Education Space (the Bologna Process) has reduced the scope for students to take optional courses, which has affected student numbers in minority subjects. Last but not least, the crisis of the humanities - the field where Catalan studies is located-has an impact on their social prestige, on their capacity to recruit students, and on the way they are perceived by university managers.

In order to make sure that Xarxa Llull faces this complex situation successfully, the Institut Ramon Llull has formulated the following strategic objectives:

1. To structurally strengthen Xarxa Llull in order to achieve a higher level of consolidation and to reinforce the institutional presence of Catalan studies in the universities. The situation we have described above poses a threat to the position of Catalan studies. Consequently, consolidating existing projects and making progress in terms of curricular development both at undergraduate and postgraduate levels will be our main priorities.

2. To link the competitiveness of Catalan studies with the productivity and quality of research in this field. This will be done by means of boosting the programme of visiting chairs and research centres, and by introducing new funding schemes to stimulate research in Catalan studies.

3. To enhance the visibility of Catalan culture in the universities where it is taught through the cultural activities programmes, and to increase the visibility of Xarxa Llull in the Catalan-speaking territories by means of a specific communication strategy.

4. To boost the professional development of students and alumni through the expansion of our specialised training offer (developing our literary translation seminars and creating new ones in areas such as 
cultural management or multilingualism management), the implementation of a new internship programme in Catalan businesses and institutions, and the creation of new networking opportunities for students and alumni.

Some of the actions that the Institut Ramon Llull will carry out in 2017 will decisively tackle these objectives. For example, the new institutional collaboration established between the IRL and the Generalitat Valenciana (the government of the region of Valencia) will make it possible to improve the funding for Catalan studies at several European universities and to introduce Catalan language teaching in a number of Spanish universities.

The entrance of the Government of the Balearic Islands into the consortium of the Institut Ramon Llull will provide us with the resources to establish a visiting chair in Catalan studies in Germany, and a centre for Catalan studies in Poland, and to fund a doctoral studentship for Xarxa Llull students. On the other hand, the invitation to Catalonia and the Balearic Islands as guests of honour of the Bologna International Book Fair, the most important in the world in the field of literature for children and young adults, will provide the opportunity and the setting for a Catalan-Italian literary translation seminar for Italian students (a programme eminently oriented towards professional development) and for high-visibility events such as an academic conference on Catalan children's literature.

Finally, we will begin implementing a student internship programme in businesses and institutions of Catalonia and the Balearic Islands, which in its initial phase will be addressed to the students of the United Kingdom and Ireland; this programme will allow students to apply the knowledge they have acquired at university, to improve their linguistic competence in Catalan, and to develop skills that will be useful in their future professional lives.

We believe that these policies will not only ensure the continuity of the Catalan language and culture at universities abroad, but will do so by boosting academic excellence, facilitating the reproduction of the discipline, helping students in their access to the labour market, and enhancing governmental efforts in the international promotion of Catalan culture by increasing its visibility in prestigious environments. Beyond these goals, Xarxa Llull has become an essential instrument for Catalan as a medium-sized European language to face the challenges of globalisation and achieve an international presence. 